\title{
EMDR, ADCs, NDEs, and the Resolution of Loss
}

To the Editor:

I commend Allan Botkin for publishing his interesting and provocative article in the Spring 2000 issue of the Journal on inducing afterdeath communications (ADCs) using eye-movement desensitization and reprocessing (EMDR). EMDR is an exciting addition to other methods of treating post-traumatic stress disorder (PTSD). And that someone else has linked EMDR to near-death experiences (NDEs) and ADCs is extremely exciting to my wife, Sharon Horacek, and to me. Sharon is a trained level I and level II practitioner of EMDR and she and I presented a paper at the EMDR International Association Conference held in Las Vegas in June, 1999, in which we discussed using EMDR to treat the traumatic and stressful events that often trigger NDEs, trauma sometimes associated with NDEs themselves, and trauma connected with some of the aftereffects of NDEs (Horacek and Horacek, 1999). Our paper included detailed information on using EMDR with near-death experiencers. Also, Sharon has used EMDR in numerous other situations involving trauma, including persons suffering PTSD grief reactions.

Botkin's article gave a detailed and clear description of how EMDR developed and how he has used it to induce ADCs in several clients. But I do have a couple of concerns about some of his views on NDEs and, especially, his understanding of grieving and his view that EMDR-induced ADCs have brought about the "complete resolution of loss" in his clients. My concerns do not detract from my view that Botkin is involved in a very important treatment modality that shows great promise for offering comfort to grievers who are exhibiting PTSD symptoms.

My first concern involves Botkin's view of what constitutes an NDE. He wrote about the sequence of events in NDEs originally described by Raymond Moody (1975): "It should be noted that the sequence is not invariant, and frequently only one or a few of the elements are reported" (Botkin, 2000, p. 206, italics added). This is a curious definition of NDEs 
to use in a research article, rather than using one of the two well-known weighted scales commonly used to quantify NDEs with minimum cutoff scores to define an NDE (Greyson, 1983, 1990; Ring, 1980). One robin does not make a spring. If the one characteristic NDE element a person reports is leaving the body or entering a tunnel, then that experience is generally called an out-of-body experience or a tunnel experience rather than an NDE. Experiencing one element or just a few would usually not come close to meeting the minimum cutoff score to qualify as an NDE on either standard scale. In the research literature, out-of-body or tunnel experiences or events comprised of just a few typical NDE features are also sometimes referred to as $N D E$-related or $N D E$-like phenomena. Consequently, some clients that Botkin might have called NDErs might not qualify as such if a more precise and accurate measure were applied.

My second concern is more serious than the first because it involves what Botkin claimed was the outcome of his EMDR-induced ADCs. No less than 13 times Botkin wrote that inducing ADCs led to the "complete resolution of grief" or the "complete resolution of the loss." Since this claim was repeated so often and included in the article abstract, one would expect that Botkin would first have explained what that phrase means and second have included both evidence of such resolution and references to important works on grieving that back up Botkin's understanding of and conclusions about the grieving process. However, his article contained no references to the research literature on grief, and his conclusions were simply stated as such with little supportive evidence. I realize that Botkin was writing as a clinician rather than as a researcher, but clinical impressions should be supported by additional evidence to bolster radical conclusions.

Throughout his article, Botkin seemed to use the phrases "complete resolution of grief" and "complete resolution of loss" interchangeably. But current understandings of grieving do not tend to identify acute grief reactions as constituting the entire grieving process. The model that Botkin seemed to accept views grieving as a time-limited process in which one is gradually healed and returned to "normal." In that view, one could work through or resolve acute grief responses such as anger and guilt and eventually end or complete the grieving process. That model, which has its roots in the work of Sigmund Freud (1917/1957) and Erich Lindemann (1944), was popular in the 1970s and 1980s in the works of Colin Murray Parkes (1972), John Bowlby (1980), William Worden (1982), Beverly Raphael (1983), and Therese Rando (1984). Lindemann argued that "uncomplicated" grieving should be completed in four to six weeks. By the middle 1980s this time limit was extended to six months to a year or more. As early as 1984 a blue-ribbon committee 
sponsored by the National Academy of Science's Institute of Medicine reviewed grief research up to that point and concluded that there was no clear, fixed end point for the grieving process, that for many people the process continues for a lifetime, and that the process is much more complicated than early grief theorists thought (Osterweis, Solomon, and Green, 1984).

The latter part of the 1980 s and the 1990 s saw an explosion of research on this issue that pointed out that, although one can resolve acute grief reactions and adapt to the loss, nevertheless a basic sense of loss continues and a continuing relationship with the deceased loved one persists (Horacek, 1991, 1995; Klass, Silverman, and Nickman, 1996). C. S. Lewis (1963) wrote, in describing his grief over the death of his wife, that the basic sense of loss is like an amputation or dismemberment. That is, a person who has a leg amputated might work through a series of grief reactions, learn to function without the use of the leg, and adapt to the loss; yet to the extent that each morning the person wakes up to the experience that the leg is still missing, the basic sense of loss continues indefinitely.

Botkin claimed that inducing $\mathrm{ADCs}$ led to the complete resolution of grief and the complete resolution of the loss. I can accept that EMDRinduced $\mathrm{ADCs}$ can completely resolve the trauma associated with grief reactions; that is what EMDR is all about. But it is difficult for me to accept from Botkin's description that these $\mathrm{ADCs}$ completely resolve the basic sense of loss for his clients and that this aftereffect continues after the sessions. In the five cases Botkin summarized, there was no direct quotation from his clients that resolution of the basic sense of loss occurred. It may have been Botkin's clinical impression that that occurred, but he did not provide convincing evidence in his clients' words. Resolving grief trauma is not the same as resolving the basic sense of loss, and Botkin's clients did not report that they no longer missed their deceased loved ones.

Again, I think that Botkin's use of EMDR-induced ADCs shows great promise for offering comfort to grievers exhibiting PTSD symptoms associated with the loss of a loved one. But I am unconvinced that such a method can completely resolve the basic sense of loss.

\section{References}

Botkin, A. L. (2000). The induction of after-death communications utilizing eyemovement desensitization and reprocessing: A new discovery. Journal of Near-Death Studies, 18, 181-209.

Bowlby, J. (1980). Loss: Sadness and depression. New York, NY: Basic Books. 
Freud, S. (1957). Mourning and melancholia. In Strachey, J. (Ed.), The standard edition of the complete psychological works of Sigmund Freud, Volume 14 (pp. 237-258). London, England: Hogarth Press. (Original work published 1917)

Greyson, B. (1983). The Near-Death Experience Scale: Construction, reliability, and validity. Journal of Nervous and Mental Disease, 171, 369-375.

Greyson, B. (1990). Near-death encounters with and without near-death experiences: Comparative NDE Scale profiles. Journal of Near-Death Studies, 8, 151-161.

Horacek, B. J. (1991). Toward a more viable model of grieving and consequences for older persons. Death Studies, 15, 459-472.

Horacek, B. J. (1995). A heuristic model of grieving after high-grief deaths. Death Studies, 19, 21-31.

Horacek, B. J., and Horacek, S. A. (1999, June). Using eye-movement desensitization and reprocessing (EMDR) with near-death experiencers (NDErs). Paper presented to the EMDR International Association Conference, Las Vegas, NV.

Klass, D., Silverman, P. R., and Nickman, S. L. (Eds.). (1996). Continuing bonds: New understandings of grief. Washington, DC: Taylor and Francis.

Lewis, C. S. (1963). A grief observed. New York, NY: Seabury Press.

Lindemann, E. (1944). Symptomatology and management of acute grief. American Journal of Psychiatry, 101, 141-148.

Moody, R. A. (1975). Life after life. Covington, GA: Mockingbird Books.

Osterweis, M., Solomon, F., and Green, M. (Eds.). (1984). Bereavement: Reactions, consequences, and care. Washington, DC: National Academy Press.

Parkes, C. M. (1972). Bereavement. New York, NY: International Universities Press.

Rando, T. A. (1984). Grief, dying, and death: Clinical interventions for caregivers. Champaign, IL: Research Press.

Raphael, B. (1983). The anatomy of bereavement. New York, NY: Basic Books.

Ring, K. (1980). Life at death: A scientific investigation of the near-death experience. New York, NY: Coward, McCann and Geoghegan.

Worden, J. W. (1982). Grief counseling and grief therapy: A handbook for the mental health practitioner. New York, NY: Springer.

Bruce J. Horacek, Ph.D. Department of Gerontology University of Nebraska at Omaha Omaha, NE 68182-0202 e-mail: bhoracek@unomaha.edu 